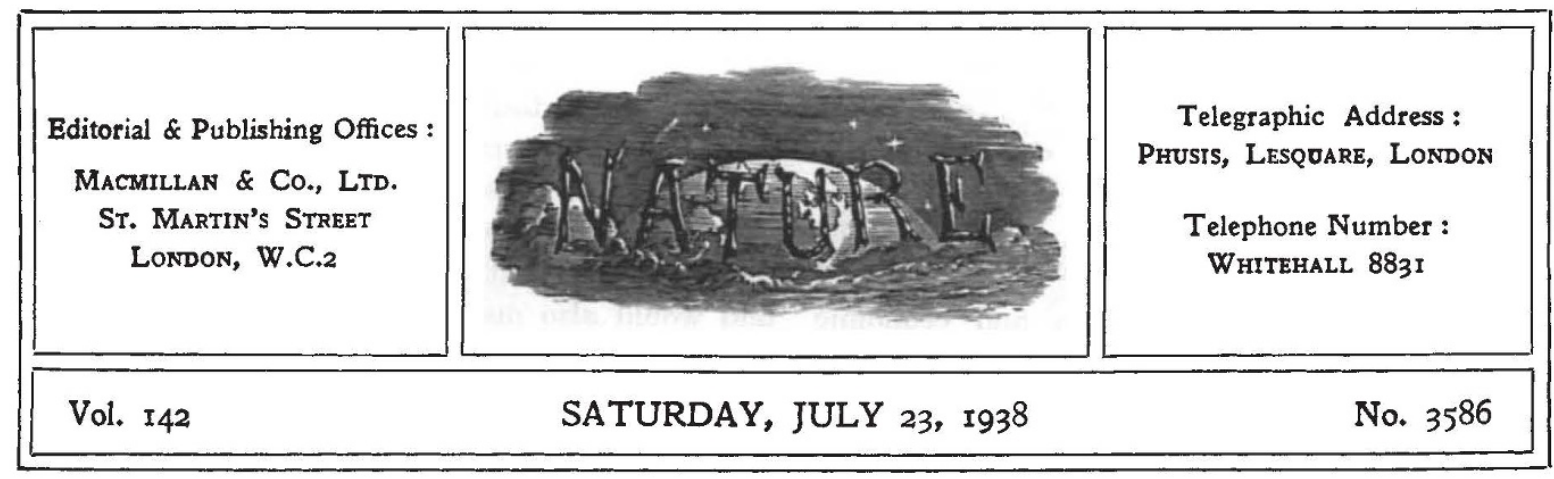

\title{
Co-operation in World Affairs
}

$\mathrm{T}$ HE annual reports in which the Director of the International Labour Organization surveys world industrial conditions owe their exceptional value not only to the large resources of knowledge upon which they draw, their wide outlook and measured but unequivocal judgments, but also to the admirable way in which Mr. H. B. Butler, avoiding excessive occupation with the detail of the work of the Organization, has given a balanced estimate of tendencies and changes in the economic and industrial situation, for which the scientific worker no less than the economist or statesman should be grateful. Mr. Butler's latest and last report* is no exception, and his review of current conditions is followed by an appreciation of the changed distribution of economic power in the world which should facilitate judgment as to the extent or severity of the recession in trade.

On the purely economic side, Mr. Butler is indeed fairly hopeful. Notwithstanding the continued political unrest and the hindrances deliberately put in the way of international trade, the world has struggled back to a prosperity which if anything surpasses the level of well-being in 1929. In spite of the severity of the American depression, he anticipates an early resumption of activity and sees some signs of greater international co-operation in trade and in currency matters.

This optimism is, however, restrained, and against this prosperity $\mathrm{Mr}$. Butler sounds two notes of warning. First, the present is an unstable prosperity, and in part issues precariously from vast expenditure on armaments and the outlay of borrowed money. Peace as well as prosperity depend largely on international trade. The effort of nations to live more and more to themselves,

*International Labour Office. Twenty-fourth Session, Geneva, 1938. Report of the Director. Pp. 81. (Geneva: International Labour Office.) 18.6d. paper, 28. 6 d. cloth. the pursuit of policies which make it imprudent to be dependent on other countries for essential supplies, and consequent disengagement so far as possible from a world economic system-these all menace such comparative prosperity as we still enjoy. While the energies of every great nation are primarily devoted to war, economic development encased in a military strait-jacket, and social welfare subordinated to the construction of guns, warplanes and battleships, expectation of the future must be tempered with anxiety rather than hope.

Secondly, Mr. Butler contrasts what prosperity at present exists with what might be enjoyed in a different atmosphere. It is certain that genuine prosperity might have been more abundant and the prospects of endurance greater had not an excessive portion of the wealth of almost every country been diverted to war purposes. As the International Chamber of Commerce recognized at Berlin last year, in all countries the rapid progress of science and invention and modern methods of production and transport would permit of the standards of living being greatly improved, provided the world would co-operate in rational distribution. In an atmosphere of autarchy or national competition, there is no prospect of attaining the standard of feeding, clothing, health, housing, working hours or leisure which the vast technical progress of this century has brought within our grasp.

It is well therefore to be reminded by this sober review that in spite of all the national experiments, many of which have achieved a considerable measure of success, a high standard of living cannot be achieved by national effort alone. No country can realize its full economic and social potentiabilities except as a part of the world 
community. Failure to recognize this truth is not merely the gravest threat to prosperity everywhere. The progressive subordination of the whole national life and the activity of every individual to the requirements of the State, the cramping and distortion of individual freedom and economic expansion are already blocking some of the main lines of social advance and now threaten to sap the social edifice which this generation has raised.

The sombre picture which Mr. Butler gives is one which requires careful consideration by all thinking men, including scientific workers as such. Only by a determined effort can the present progressive deterioration be averted, and that effort is now demanded in the interests of science itself. Moreover, though science cannot take more than a small part of the blame for mankind's failure to utilize scientific knowledge to the fullest advantage in service of man's daily needs or for the use of scientific knowledge for destructive purposes, scientific workers are also citizens, and as such must accept the greater responsibilities which their knowledge and training entail.

It is not, of course, within the scope of Mr. Butler's report to suggest ways and means of securing action. He can only give a warning, and it is one to be heeded by scientific workers. Moreover, the report is not without certain suggestions which merit their special attention. In discussing the question of unemployment, Mr. Butler points out that although in most countries the employment situation was much better in 1937 than at any time since 1929, due partly to demands for war material and the expansion of armed forces, there is in many countries a marked shortage of skilled workers. This is due partly to military requirements, but mainly to the failure to educate a sufficient number of apprentices during the depression. Accordingly it is suggested that the whole question of industrial education and training for industry should be reconsidered.

This is a question with which scientific workers are very closely concerned. Even in regard to the problem of training for technical positions in industry, professional associations cannot be said to have given anything like adequate attention to the many important questions involved. The great demand in mechanized industry for highly trained workers possessing a wide range of technical knowledge cannot be met without their co-operation. A part altogether from its reaction on the position and efficiency of the scientific worker in industry, the solution of this problem has social aspects at least as important as its effect on industrial efficiency. The provision of such highly trained workers would do something to counteract the illeffects of the monotony of mechanization which have sprung up with the passing of the craftsmen, and would also make for the mobility of labour and lessen the tendency of specialized work to create men who are unemployable in other capacities.

Here and elsewhere, as in its references to the work on nutrition, the extension of the principle of social insurance, the continued tendency towards shorter hours of work, the report marks signs of progress and opportunities for further advance by international co-operation. The main value of the report lies, however, in the world picture it gives and the clear warning it sounds as to the danger of certain policies which are widely countenanced to-day. No thoughtful reader can fail to recognize the necessity for facing a changed situation and evolving new methods to deal with it. The very expansion of the activities of the International Labour Organization itself to meet the increased need for international co-ordination with the passing of economic laissez-faire, the increased importance attached to the problems of agriculture, migration, housing, nutrition, indigenous labour, attest the existence of an immense amount of international co-operation even in these days of anxiety and unrest, and forecast the immense opportunities of development, in many of which scientific workers have their part to play.

Beyond this, the distribution of economic power is shifting. The economic development of the Far East is inevitable, and there is little doubt that Europe will ultimately lose some of its pre-eminence in the economic sphere, a process likely to be accentuated by the division of Europe into groups pursuing different social objectives and working upon different economic principles. Here again are problems to be worked out rather than fought out, and Mr. Butler's survey is pregnant with challenge to commercial and industrial states. manship.

Ultimately, however, it is the challenge to men of good will everywhere to unite in the task of securing for all mankind the advantages which the achievements of modern technology have put within our grasp that most commends the report. The prostitution of scientific knowledge to destructive purposes and the pursuit of retrograde nationa economic policies threaten the whole social edifice and with it the freedom and 
continuity of scientific work itself. For scientific workers, Mr. Butler poses clearly the question whether they are prepared to take up the arduous task with their fellow citizens of evolving means of arresting the drift to disaster, making their own special contributions to the solution of specified technical problems, or by their indifference and neglect allowing the forces of disruption and retrocession to gain strength until scientific workers are overwhelmed with the rest.

\section{British and German University Enrolments}

JN another column (p. 175) we print an article on "Numerical Changes in the German Student Body" by Dr. E. Y. Hartshorne of Harvard, author of "German Universities and National Socialism". The main conclusions in Dr. Hartshorne's article may be summarized by saying that the reduction in number of students in German universities and seats of higher learning was approximately 42 per cent between 1932 and 1937, so that where there were a hundred in 1932 there were only fifty-eight in 1937 . The process has since continued, and it seems probable that there are now not more than half the number of students in Germany that there were in 1932 . Of the survivors, more than a third-approximately 34 per cent in 1937-were students of medicine. The great reductions have been in humanities, in 'pure' science and in law and allied studies. These conclusions naturally suggest an inquiry whether there are similar tendencies, if of a less degree, in the British student body. A preliminary investigation of the returns of the Universities Grants Committee shows that this question must be answered in the negative.

Since the academic year 1933-34, there has been a slight fall in the number of students entering British universities. The changes are of the order which those who administer universities regard as normally associated with fluctuations of prosperity. There is no reason to suppose that they have any permanent or deeply seated social causation. Moreover, within the British student body itself there are only minor fluctuations in the distribution of numbers. The British classifications are scarcely comparable to the German, but, with due reservations, it is possible to construct tentatively a comparative table of student groups in Great Britain and Germany, expressed as percentages of the total enrolment in each country. Such a table can be interpreted, however, only in the light of the enormous absolute fall in the total number of German students.

It will be seen that the highly significant drop, both relative and absolute, in the sciences and in engineering in the greatly diminished German student body has no parallel in the British universities. A distant analogy may be suggested in the rise in the percentage in 'medical studies' in the two countries. The relatively greater attention paid to these by British students is, however, easily explicable by the rise in importance of the social services in Britain and the increased demand for British trained medical men overseas.

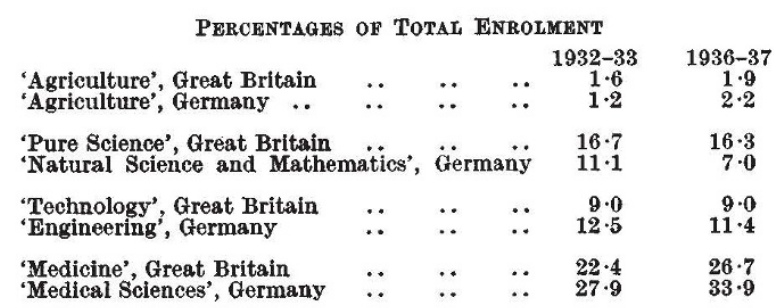

So far as foreign students are concerned, the movement in Great Britain is in the opposite direction to that in Germany. The report of the Universities Grants Committee notes that the number of students from overseas in British universities reached in 1936-37 the record figure of 6,792. This is an increase of about 50 per cent over 1932-33. Dr. Hartshorne records a decrease in the number of foreign students in Germany from 6,693 in $1932-33$ to 4,768 in 1936-37. The "Universities Year Book of the British Empire" shows the countries of origin of students from abroad in British universities. The numbers from Germany in the six years $1932-33$ to $1936-37$ were respectively $169,375,436,439,416,444$. These may be compared with the corresponding numbers of students from Holland: 46, 55, 42, $55,69,58$; and from France : 80, 73, 81, 78, 76, 50 . We leave our readers themselves to judge whether the increase in the number of students from Germany since 1933 is due to an increased recognition of the advantages of study in Great Britain or to the racial and other limitations which are now imposed in that country upon entrance to universities. 